\title{
Safety of vaginal birth after single previous lower segment caesarean: a retrospective analysis of 200 cases
}

\author{
Renu Jain* \\ Department of Obstetrics and Gynecology, Gajra Raja Medical College, Gwalior, Madhya Pradesh, India \\ Received: 17 May 2018 \\ Accepted: 21 May 2018 \\ *Correspondence: \\ Dr Renu Jain, \\ E-mail: renujain_1979@ rediffmail.com \\ Copyright: (C) the author(s), publisher and licensee Medip Academy. This is an open-access article distributed under \\ the terms of the Creative Commons Attribution Non-Commercial License, which permits unrestricted non-commercial \\ use, distribution, and reproduction in any medium, provided the original work is properly cited.
}

\begin{abstract}
Background: Vaginal birth after Caesarean delivery (VBAC) has long been proposed as a viable measure to reduce overall Caesarean delivery rates. The objective of present study was to assess predictive factors and to study outcome of pregnancy in women with one previous lower segment caesarean section underwent trial of scar, in author's hospital setting.

Methods: This retrospective analysis of 200 pregnant women with one previous lower segment caesarean section underwent trial of scar, was carried out over a period of one year, in department of Obstetrics and Gynaecology, Gajra Raja Medical College, Gwalior (M.P.). The maternal and neonatal data and data concerning the course of delivery were reviewed and subjected to statistical analysis.

Results: The success rate of VBAC was $36 \%$. Young maternal age, gestational age <40 weeks, neonate birth weight 2.5-3 kg, admission in active phase of labor, previous caesarean for malpresentation, meconium stained liquor and fetal distress, were associated with successful VBAC. The commonest indication of repeat caesarean section was nonprogress of labor in $34.37 \%$ women. Admission rate to neonatal intensive care unit was less in VBAC (2.77\%) than in repeat caesarean section group (7.03\%). There was one case of uterine rupture. There were 3 perinatal deaths and no maternal deaths.

Conclusions: Women with a prior caesarean section are at increased risk of subsequent caesarean. Vaginal birth after caesarean should be encouraged in selected cases to reduce the risks of repeated caesarean sections. However, in the event of a failed trial, there is a definite increase in neonatal and maternal morbidity which is also reflected in our study.
\end{abstract}

Keywords: Caesarean section, Neonatal and maternal morbidity, Trial of labor, VBAC

\section{INTRODUCTION}

Caesarean section represents the most significant operative intervention in all of Obstetrics. Caesarean section rates have risen worldwide. Performance of elective repeat caesarean is one of the main reasons for the rise in caesarean section rates, together with fetal distress, dystocia and breech presentation. ${ }^{1}$

Vaginal birth after Caesarean section is associated with shorter maternal hospitalizations, less blood loss and fewer transfusions, fewer infections and fewer thromboembolic events than Caesarean delivery. Uterine rupture and its associated complications are increased with a trial of labor. Several reports have indicated that the absolute risk of uterine rupture attributable to a trial of labor is about 1 per $1000 .^{1}$

Compared with vaginal delivery, Caesarean birth is associated with increased risk of anaesthesia complications, hemorrhage, damage to the bladder and other organs, pelvic infection and adhesion formation. ${ }^{1}$ 
There are considerable data to show that repeated ERCS is associated with an increased risk of placenta praevia, placenta accreta and surgical complications at the time of subsequent pregnancy and delivery, such as hysterectomy. ${ }^{2}$

The most appropriate mode of subsequent delivery of women with prior Caesarean birth continues to be a subject of intense research and debate in contemporary Obstetric practice. Vaginal birth after Caesarean delivery (VBAC) has long been proposed as a viable measure to reduce overall Caesarean delivery rates in both developed and developing countries. It has been found to be safe with careful patient selection and good management of labor with success rates ranging between $60 \%$ to $80 \%$. $^{3}$

There is a consensus (National Institute for Health and Care Excellence (NICE), Royal College of Obstetricians and Gynaecologists (RCOG), American College of Obstetricians and Gynecologists (ACOG) and National Institutes of Health (NIH) that planned VBAC is a clinically safe choice for the majority of women with a single previous lower segment caesarean delivery. Such a strategy is also supported by health economic modelling. ${ }^{2}$ It is worth remarking that there is no reliable and demonstrable attribute that always correctly identifies and accurately predicts those women with a prior Caesarean who will achieve successful VBAC. ${ }^{3}$

In author's hospital, there is a practice to allow patients who have had one previous lower segment Caesarean section to go into labor in the absence of a recurrent indication for caesarean section or a new indication that precludes vaginal delivery. This study was done to estimate the rate of vaginal delivery and repeat caesarean section in pregnancy with previous one lower segment Caesarean section, to study the factors associated with successful vaginal delivery, to study the indications of repeat caesarean section and to study maternal and fetal outcomes.

\section{METHODS}

This retrospective study was carried out at Department of Obstetrics and Gynaecology, Kamla Raja Hospital, Gwalior (M.P.), during a period of 1 year from July 2016 to June 2017. Case records of 200 pregnant women with previous one lower segment caesarean section, who were given trial of scar were reviewed.

Criteria for trial of scar were women with single previous lower segment transverse caesarean section, >37 weeks of gestation, spontaneous onset of labor, singleton pregnancy, vertex presentation, no cephalopelvic disproportion, no fetal anomaly associated with mechanical difficulties at birth (such as hydrops, fetal ascitis, hydrocephalus, omphalocele or cystic hygroma), without abnormal placentation confirmed on ultrasound and willing for trial of scar. The following patients were excluded: not willing for trial of scar, with previous classical cesarean section, previous inverted $\mathrm{T}$ or $\mathrm{J}$ shaped incision, fetal demise, lethal fetal anomalies, or incomplete medical records. Information regarding sociodemographic characteristics, Obstetric history, gestational age, medical history and history of full term vaginal delivery prior to or following previous caesarean section was collected. Detail information about previous caesarean section like indication, gestational age at which it was performed, place where it was performed, and fetal outcome was collected.

Maternal outcomes in terms of mode of delivery, indication of emergency repeat caesarean section and postpartum maternal morbidity like units of blood transfused, postpartum haemorrhage, injury to bladder and genital tract, urinary tract infection and wound dehiscence were noted. Intra Operative findings like presence of adhesions, integrity of scar etc. were also recorded. Neonatal outcomes noted were apgar score at 1 minutes and 5 minutes, meconium stained liquor, still birth, birth weight and admission to neonatal intensive care unit.

\section{The following definitions are provided}

- Trial of labor: A planned attempt to labor by a woman who has had a previous cesarean delivery, also known as trial of labor after cesarean (TOLAC).

- Vaginal birth after cesarean delivery (VBAC): Vaginal delivery after a trial of labor; that is, a successful trial of labor.

- Unsuccessful trial of labor: Delivery by cesarean section in a woman who has had a trial of labor; sometimes referred to as a "failed" trial of labor

- Elective repeat cesarean delivery (ERCS): Planned cesarean delivery by a woman who has had one or more prior cesarean deliveries. The delivery may or may not be scheduled.

Analysis was done with the excel computer software and results were reported as percentage.

\section{RESULTS}

Among 200 women who underwent trial of scar $72(36 \%)$ women delivered vaginally, While 128 (64\%) women had to deliver by emergency repeat caesarean section (Table $1)$.

Table 1: Mode of delivery following trial of labor birth after caesarean section.

\begin{tabular}{|lll|}
\hline Mode of delivery & $\begin{array}{l}\text { No. of } \\
\text { cases }\end{array}$ & Percent \\
\hline $\begin{array}{l}\text { Spontaneous vaginal delivery } \\
\text { (successful TOL) (VBAC) }\end{array}$ & 72 & 36 \\
\hline EmRCS (Failed TOL) & 128 & 64 \\
\hline Total & 200 & 100.0 \\
\hline
\end{tabular}

TOL - Trial of labor, EmRCS - Emergency Repeat Caesarean Section 
Table 2 demonstrates demographic characteristics of the patients. Majority of women were in the age group 25-29 years. Among women who delivered vaginally, 4 (5.55 $\%$ ) women were in 30-35 years age group and none was $>35$ years, while among women who delivered by repeat Caesarean Section, 18 (14.06\%) women were in $30-35$ years age group and $2(1.56 \%)$ women were $>35$ years. Majority of women were unbooked and were referred from rural areas.

Table 2: Demographic characteristics of pregnant women.

\begin{tabular}{|c|c|c|}
\hline \multirow[t]{2}{*}{ Characteristic } & $\begin{array}{l}\text { Successful } \\
\text { trial of labor } \\
\text { (VBAC) } \\
(\mathrm{n}=72)\end{array}$ & $\begin{array}{l}\text { Failed trial of } \\
\text { labor (Emergency } \\
\text { repeat CS) } \\
(\mathrm{n}=128)\end{array}$ \\
\hline & No. $(\%)$ & No. $(\%)$ \\
\hline \multicolumn{3}{|c|}{ Maternal age in years } \\
\hline$<20$ & 0 & 0 \\
\hline $20-24$ & $30(41.66)$ & $48(37.5)$ \\
\hline $25-29$ & $38(52.77)$ & $60(46.87)$ \\
\hline $30-35$ & $4(5.55)$ & $18(14.06)$ \\
\hline$>35$ & 0 & $02(1.56)$ \\
\hline \multicolumn{3}{|l|}{ Locality } \\
\hline Rural & $44(61.11)$ & $77(60.15)$ \\
\hline Urban & $28(38.88)$ & $51(39.84)$ \\
\hline \multicolumn{3}{|l|}{ Referral status } \\
\hline Direct & $50(69.44)$ & $105(82.03)$ \\
\hline Referred & $22(30.55)$ & $23(17.96)$ \\
\hline \multicolumn{3}{|l|}{ Booking status } \\
\hline Booked & $24(33.33)$ & $51(39.84)$ \\
\hline Unbooked & $48(66.66)$ & $77(60.15)$ \\
\hline
\end{tabular}

Table 3: Obstetric characteristics of pregnant women.

\begin{tabular}{|c|c|c|c|}
\hline \multirow[t]{2}{*}{ Characteristic } & \multirow[t]{2}{*}{ No. } & $\begin{array}{l}\text { Successful } \\
\text { trial of } \\
\text { labor } \\
(\mathrm{n}=72)\end{array}$ & $\begin{array}{l}\text { Failed trial } \\
\text { of labor } \\
\text { (Emergency } \\
\text { repeat CS) (n } \\
=128 \text { ) }\end{array}$ \\
\hline & & No. $(\%)$ & No. $(\%)$ \\
\hline $\begin{array}{l}\text { History of vaginal } \\
\text { delivery before or } \\
\text { after previous CS }\end{array}$ & 6 & $2(33.33)$ & $4(66.66)$ \\
\hline \multicolumn{4}{|c|}{ Interpregnancy interval } \\
\hline$<18$ months & 32 & $10(31.25)$ & $22(68.75)$ \\
\hline$>18$ months & 168 & $62(36.90)$ & $106(63.09)$ \\
\hline \multicolumn{4}{|l|}{ Intrapartum } \\
\hline Latent phase & 130 & $22(16.92)$ & $108(83.07)$ \\
\hline Active phase & 70 & $50(71.42)$ & $20(28.75)$ \\
\hline \multicolumn{4}{|c|}{ Gestational age at delivery } \\
\hline$<40$ weeks & 172 & $70(40.69)$ & $102(59.30)$ \\
\hline$>40$ weeks & 28 & $2(7.15)$ & $26(92.85)$ \\
\hline \multicolumn{4}{|l|}{ Infant birth weight } \\
\hline$<2.5 \mathrm{~kg}$ & 26 & $10(38.46)$ & $16(61.53)$ \\
\hline $2.5-3 \mathrm{~kg}$ & 134 & $58(43.28)$ & $76(56.71)$ \\
\hline$>3 \mathrm{~kg}$ & 40 & $4(10)$ & $36(90)$ \\
\hline
\end{tabular}

Among women with history of vaginal delivery, $33.33 \%$ delivered vaginally and $66.66 \%$ by repeat Caesarean section.

The chances of vaginal delivery were $31.25 \%$ when inter pregnancy interval was $<18$ months and $36.90 \%$ when interpregnancy interval was $>18$ months. VBAC rate is more $(71.42 \%)$ when women were in active phase of labor at the time of admission than when were in latent phase $(16.92 \%)$.

In women with gestational age $<40$ weeks, vaginal delivery occurred in $40.69 \%$ women, while only 2 $(7.15 \%)$ women delivered vaginally when gestational age was $>40$ weeks. It shows that there was an increase in failed trial of labor in those after 40 weeks.

VBAC rate was $43.28 \%$ when birth weight was between 2.5-3 kg, while vaginal delivery occurred in only $10 \%$ women when birth weight was $>3 \mathrm{~kg}$. Birth weight $>3 \mathrm{~kg}$ increased the chances of caesarean section $(90 \%)$ (Table $3)$.

Table 4: Indication of previous caesarean section and mode of delivery in the index pregnancy.

\begin{tabular}{|c|c|c|c|}
\hline $\begin{array}{l}\text { Indication of } \\
\text { previous } \\
\text { caesarean } \\
\text { section }\end{array}$ & $\begin{array}{l}\text { No. of } \\
\text { cases } \\
(n=200)\end{array}$ & $\begin{array}{l}\text { Successful } \\
\text { trial of } \\
\text { labor } \\
\text { (VBAC) } \\
(n=72) \\
\text { No. }(\%)\end{array}$ & $\begin{array}{l}\text { Emergency } \\
\text { Repeat } \\
\text { caesarean } \\
\text { section } \\
(n=128) \\
\text { No. }(\%)\end{array}$ \\
\hline $\begin{array}{l}\text { Non-progress of } \\
\text { labor }\end{array}$ & 78 & $28(35.89)$ & 50 \\
\hline CPD & 20 & $2(12)$ & $18(90)$ \\
\hline $\begin{array}{l}\text { Breech } \\
\text { presentation }\end{array}$ & 22 & $14(63.63)$ & $8(36.36)$ \\
\hline Transverse lie & 22 & $10(45.45)$ & $12(54.54)$ \\
\hline $\begin{array}{l}\text { Antepartum } \\
\text { haemorrhage }\end{array}$ & 6 & $4(66.66)$ & $2(33.33)$ \\
\hline Fetal distress & 4 & $4(100)$ & 0 \\
\hline MSL & 10 & $10(100)$ & 0 \\
\hline Oligohydramnios & 12 & 0 & $12(100)$ \\
\hline $\begin{array}{l}\text { Severe } \\
\text { preeclampsia }\end{array}$ & 4 & 0 & $4(100)$ \\
\hline Eclampsia & 2 & $2(100)$ & 0 \\
\hline $\begin{array}{l}\text { Postdated } \\
\text { pregnancy with } \\
\text { failed induction }\end{array}$ & 8 & 0 & $8(100)$ \\
\hline Cord around neck & 4 & $4(100)$ & 0 \\
\hline Obstructed labor & 2 & 0 & $2(100)$ \\
\hline $\begin{array}{l}\text { Premature rupture } \\
\text { of membranes }\end{array}$ & 6 & $4(66.66)$ & $2(33.33)$ \\
\hline
\end{tabular}

VBAC success rate was poor in cases where indication of previous caesarean was postdated pregnancy with failed induction, non-progress of labor and cephalopelvic disproportion $(0,35.89 \%$ and $12 \%$ respectively). In those who have had breech presentation, PROM, fetal distress, meconium stained liquor, there was high success rate depicted in Table 4. 
Table 5: Indication of emergency repeat caesarean section in the index pregnancy.

\begin{tabular}{|lcl|}
\hline Indication of repeat caesarean & No. & Percent \\
\hline section & 22 & 17.18 \\
\hline Fetal distress & 20 & 15.62 \\
\hline Meconium stained liquor & 44 & 34.37 \\
\hline Non-progress of labor & 6 & 4.68 \\
\hline Second stage arrest & 36 & 28.12 \\
\hline Scar tenderness (risk of scar rupture) & 128 & 100 \\
\hline Total & & \\
\hline
\end{tabular}

The commonest indication of emergency repeat caesarean section was non-progress of labor in 44 (34.37\%) women. Other common indications were impending rupture (diagnosed by the presence of scar tenderness) in 36 $(28.12 \%)$ women and fetal distress in $22(17.18 \%)$ women (Table 5).

Table 6: Fetal outcome according to mode of delivery.

\begin{tabular}{|lll|}
\hline Fetal Outcome & $\begin{array}{l}\text { Trial of scar } \\
\text { Vaginal delivery } \\
\text { (successful TOL) } \\
(\mathbf{n = 7 2 )}\end{array}$ & $\begin{array}{l}\text { EmRCS } \\
\text { (Failed TOL) } \\
\text { (n=128) }\end{array}$ \\
\hline No. $(\%)$ & No. $(\%)$ \\
\hline Alive and healthy & $70(97.22)$ & $117(91.40)$ \\
\hline $\begin{array}{l}\text { Still Birth } \\
\text { Nursery }\end{array}$ & 0 & $2(1.56)$ \\
Admission & $2(2.77)$ & $9(7.03)$ \\
\hline
\end{tabular}

Table 7: Intraoperative findings.

\begin{tabular}{|lll|}
\hline Intraoperative findlings & Number & Percent \\
\hline Dense adhesions & 21 & 16.40 \\
\hline Meconium stained liquor & 10 & 7.81 \\
$\begin{array}{l}\text { Bladder adhered to previous } \\
\text { scar }\end{array}$ & 6 & 4.68 \\
\hline Scar dehiscence & 10 & 7.81 \\
\hline Scar rupture & 1 & 0.78 \\
\hline Fibroid in lower uterine segment & 1 & 0.78 \\
\hline Post partum haemorrhage & 2 & 1.56 \\
\hline
\end{tabular}

\section{DISCUSSION}

Vaginal birth after caesarean section has been advocated as a safe and practical means of reducing overall caesarean delivery rate. It is a great challenge to identify the women who are most likely to have a successful trial of labor. The decision to allow a patient a trial of labor after a previous caesarean section is influenced by a complex interplay of factors including obstetric history, patients' wishes and obstetricians' perception of the risks of labor and the likelihood of success in any particular case.

In present study, among 200 women who underwent trial of scar $72(36 \%)$ women delivered vaginally, while 128
(64\%) women had to deliver by emergency repeat caesarean section. Successful Vaginal delivery rate of $31 \%$ following trial of scar, reported by Jha is lower than that found in present study. ${ }^{4} \mathrm{~A}$ recent Australian cohort trial reported a VBAC success rate of $43 \%$, slightly higher than present study. ${ }^{5}$ The overall VBAC success rate during the study timeframe was lower than that found in other studies by Bangal $(85 \%)$, by Ugwu $(50 \%)$ and by Jani $(60 \%){ }^{6-8}$

A lower VBAC reported in this study is attributed to unbooked and referred mothers, who came in a critical condition with a history of trial of labor and who had no documentation of their previous caesarean, which made decision for trial of labor difficult and, so usually end up with emergency caesarean section after a short trial, in order to safeguard the life of mother and fetus.

The lower VBAC success rate in this study could also be a result of more cautious use of labour-stimulating agents for women attempting $\mathrm{VBAC}$, as there is growing evidence that these can increase the risk of uterine rupture. Although induction and augmentation are not contraindicated in women with previous caesarean delivery, there remains considerable disagreement among clinicians on their use. Induction (particularly in women with an unfavourable cervix) by prostaglandins or augmentation of labour in these women are associated with a two- to three-fold increased risk of uterine rupture and around a 1.5-fold increased risk of caesarean delivery compared with spontaneous VBAC labour. ${ }^{2}$

It may be that more liberal application of induction and augmentation of labor when indicated may have increased the rate of successful VBAC at author's hospital.

Also, the probable reason for a lower rate of successful VBAC in present study was that only $3 \%$ patients (as majority of women were second gravida) who opted for a trial of labor had a history of prior vaginal deliveries as compared to $50 \%$ of the patients in the study by Landon et al. ${ }^{9}$

Demographic factors, nonclinical and past obstetric factors may predict VBAC since these factors are known prenatally and would allow clinicians to provide information on prognosis early in pregnancy. Majority of women were in age group 25-29 years, reflecting the child bearing age of most of the women. Among women who delivered vaginally, only $4(5.55 \%)$ women were in 30-35 years age group and none was > 35 years, while among women who delivered by repeat caesarean section, $18(14.06 \%)$ were in 30-35 years age group and 2 $(1.56 \%)$ were > 35 years. In a study by Knight, younger women had a higher success rate with vaginal delivery. ${ }^{10}$ Raja et al, reported that the increasing maternal age directly correlated with the risk of emergency $\mathrm{CS} .^{11}$ Doshi et al, reported that the success of VBAC declined 
significantly as the maternal age increased beyond 35 years. $^{12}$

In present study, among women with history of vaginal delivery, $33.33 \%$ delivered vaginally and $66.66 \%$ by repeat Caesarean section. But in other studies, it has been reported that patients with a history of vaginal delivery before or after caesarean section are more likely to deliver vaginally again. $6,11,13$

In present study, the chances of vaginal delivery were $31.25 \%$ when interpregnacy interval was $<18$ months and $36.90 \%$ when interpregnancy interval was $>18$ months, suggesting not much influence on VBAC rate. A short interdelivery interval allows inadequate time for postpartum healing of the previous Caesarean scar. In a study by Bujold, an interdelivery interval shorter than 18 months was associated with a significant increase of uterine rupture. ${ }^{14}$ While in study by Kessous, short interdelivery interval was not a risk factor for major maternal and neonatal complications such as uterine rupture and postpartum death. ${ }^{15}$

In present study, women who were in active phase of labor at the time of admission had better chances of vaginal delivery $(71.42 \%)$. Similar finding was reported in studies by Bangal et al. and by Birara. ${ }^{6,16}$

Many current obstetric factors related to the infant (gestational age, birth weight and infant gender) predicted VBAC followed by a cesarean delivery. In present study, in women with $<40$ weeks of gestation, vaginal delivery occurred in $40.69 \%$ women, while only $2(7.15 \%)$ women delivered vaginally when gestational age was > 40 weeks. It shows that there is an increase in failure of trial of labor in those after 40 weeks.

In present study, VBAC rate was $43.28 \%$ when birth weight was between $2.5-3 \mathrm{~kg}$, while vaginal delivery occurred in only $10 \%$ women when birth weight was $>3$ $\mathrm{kg}$. Birth weight more than $3 \mathrm{~kg}$ increases the chances of Caesarean section $(90 \%)$. In a study by Doshi et al, the success rate of VBAC was significantly higher in women who had infants weighing $<3 \mathrm{~kg} .{ }^{12}$ Estimated fetal weight should be included in the decision-making process for all women contemplating a trial of labor after cesarean delivery.

In present study, VBAC success rate was low in cases where indication of previous caesarean was postdated pregnancy with failed induction, non-progress of labor and cephalopelvic disproportion $(0,35.89 \%$ and $12 \%$ respectively). When indication of previous caesarean was breech presentation, PROM, fetal distress and meconium stained liquor, there was high VBAC success rate. Same finding was reported in a study by Raja et al. ${ }^{11}$

In study by Doshi et al, patients with prior LSCS for malpresentations had the highest rate of successful VBAC, followed by those with prior LSCS for fetal distress and patients with prior LSCS for non-progress of labor (Dystocia). ${ }^{12}$

In present study, the commonest indication of emergency repeat caesarean section was non-progress of labor in 44 $(34.37 \%)$ women. Other common indications were impending rupture (diagnosed by the presence of scar tenderness) in $36(28.12 \%)$ women, fetal distress in 22 $(17.18 \%)$ women and meconium stained liquor in 20 (15.62\%) women. Scar tenderness was elicited by pressing below and behind the pubic symphysis in between uterine contractions while engaging the woman in conversation and noting for visible wince. In a study by Latika et al, fetal distress was the most common $(36.3 \%)$ indication of repeat caesarean section followed by scar tenderness $(27.2 \%) .{ }^{17}$ In a study by Mishra et al, the most common indications for repeat emergency LSCS were non-progress of labor and failed induction of labor. $^{18}$

In present study, admission rate to neonatal intensive care unit was less in successful VBAC (2.77\%) than emergency caesarean section group $(7.03 \%)$. In present study, there were 3 perinatal deaths, 1 in VBAC group and 2 in women with failed trial of labor. Crowther CA et al, reported that the risk of fetal death or liveborn infant death prior to discharge or serious infant outcome was significantly lower for infants born in the planned ERC group compared with infants in the planned VBAC group $(0.9 \%$ versus $2.4 \%){ }^{5}$ Andrea B Pembe reported high proportion of perinatal deaths as compared to present study. ${ }^{19}$

The most worrying complication of TOLAC is uterine rupture which might result in peripartum hysterectomy with significant blood loss and /or maternal and perinatal morbidity and mortality. In present study, there was one case of uterine rupture. This patient delivered vaginally a healthy baby. Rupture was suspected after delivery of placenta as patient developed unexplained pallor and shock, so decision for emergency laparotomy was taken. On laparotomy previous scar site was found ruptured. Repair of ruptured scar was done with bilateral tubal ligation. Early diagnosis of uterine scar dehiscence or rupture followed by expeditious laparotomy and neonatal resuscitation are essential to reduce associated morbidity and mortality.

Incidence of uterine rupture $(2 \%)$ reported by Pembe et al, is higher than present study. ${ }^{19}$ The US Agency for Healthcare Research and Quality (AHRQ) meta-analysis and studies from the UK, Australia and Ireland reported a VBAC uterine rupture risk of $0.5 \%, 0.2 \%, 0.33 \%$ and $0.2 \%$ respectively. Rates of uterine rupture differ according to whether VBAC labour is spontaneous $(0.15$ $0.4 \%)$, induced $(0.54-1.4 \%)$ or augmented $(0.9-1.91 \%){ }^{2}$

It is important to note that scar dehiscence may be asymptomatic in up to $48 \%$ of women and the classic triad of a complete uterine rupture (pain, vaginal 
bleeding, fetal heart rate abnormalities) may present in less than $10 \%$ of cases. ${ }^{20}$

In present study, intra-operative complications caused major maternal morbidity. In present study, the main difficulties while doing a repeat cesarean section were difficulty in opening the abdomen due to dense adhesions in $16.40 \%$ of the cases, difficulty in separation of the bladder in $4.68 \%$ and scar dehiscence was present in $7.81 \%$ cases. Postpartum haemorrhage occurred in 2 women managed by intrauterine packing. The rate of blood transfusions was $12 \%$ in the group who had emergency caesarean section. This higher rate of transfusion can be due to added effect of blood loss during emergency surgery.

In present study, none of the deliveries were complicated by postpartum sepsis. Higher febrile morbidity after a failed trial of labor and in repeat caesarean sections reported in earlier studies has significantly reduced after advent of broad spectrum antibiotics and concern regarding postoperative infectious morbidity is not a major issue in selecting mode of delivery.

The present study had no major complications like Hysterectomy, blood transfusion, $\mathrm{PPH}$, pyrexia in patients who had successful VBAC. It has generally been accepted that vaginal delivery is associated with lower maternal morbidity and mortality rates than repeat CS.

In present study, on analyzing the incidence of maternal morbidities associated with different modes of delivery, it was found that morbidity was maximum, in patients who underwent emergency caesarean section, more so, after a failed trial of labour. Eskandar et al, reported higher maternal morbidity after repeat caesarean section than after successful vaginal birth after trial of labor. ${ }^{21}$

In present study, there were no maternal deaths, a finding similar to that reported by Latika et al. ${ }^{17}$ AHRQ9 metaanalysis showed an increased risk of maternal mortality with ERCS compared with planned VBAC (13/100 000 versus $4 / 100000) .^{22}$

\section{CONCLUSION}

Women with a prior caesarean are at increased risk of repeat caesareans. Vigilance with respect to indication at primary caesarean delivery, proper counselling for trial of scar and evaluation of patients with prior caesarean section are key to reducing the caesarean section rate. However, there is yet no confirmed method of predicting the likelihood that a trial of labor will lead to vaginal delivery for a patient with a previous low transverse caesarean section.

The VBAC success rates in cases of trial of labor may be influenced by the degree of prior selection, with high success rates to be expected when only patients with the most favpresentable prognostic features are allowed to proceed to labor.

With improved antenatal care and institutional confinement, VBAC is considered safer than repeat elective CS in a carefully selected population. However, in the event of a failed trial, there is a definite increase in neonatal and maternal morbidity which is also reflected in present study.

\section{Funding: No funding sources \\ Conflict of interest: None declared \\ Ethical approval: Not required}

\section{REFERENCES}

1. Cunningham FG, Levono KJ, Bloom SL, Hauth JC, Rouse DJ, Spong CY. Caesarean Delivery and Peripartum Hysterectomy. In: Editors, Williams Obstetrics. 23 ${ }^{\text {rd }}$ ed. New York: McGraw Hill Medical; 2010:544-567.

2. Royal College of Obstetricians and Gynaecologists. Birth After Previous Caesarean Birth. Green-top Guideline No. 45. London: RCOG; October 2015.

3. Seffah JD, Adu-Bonsaffoh K. Vaginal birth after a previous caesarean section: current trends and outlook in Ghana. J West African College of Surgeons. 2014;4(2):1.

4. Jha M. Pregnancy outcome of single previous Caesarean section. J Nepal Health Res Counc. 2009;(14):25-8.

5. Crowther CA, Dodd JM, Hiller JE, Haslam RR, Robinson JS. Birth After Caesarean Study Group. Planned vaginal birth or elective repeat caesarean: patient preference restricted cohort with nested randomised trial. PLoS Med. 2012;9(3):e1001192

6. Bangal VB, Giri PA, Shinde KK, Gavhane SP. Vaginal birth after cesarean section. N Am J Med Sci. 2013;5(2):140.

7. Ugwu GO, Iyoke CA, Onah HE, Egwuatu VE, Ezugwu FO. Maternal and perinatal outcomes of delivery after a previous Cesarean section in Enugu, Southeast Nigeria: A prospective observational study. Int J Women's Health. 2014;6:301.

8. Jani RS, Munshi DS. Management of pregnancy with previous lower segment Caesarean section in Modern obstetric practice. NHL J Med Sci. 2013;2(2):59-63.

9. Landon MB, Hauth JC, Leveno KJ, Sponge YC, Leindecker S, Varner MW. et al. Maternal and perinatal outcomes associated with a trial of labor after prior caesarean delivery. $\mathrm{N}$ Engl $\mathrm{J}$ Med. 2004;351:2581-9.

10. Knight HE, Gurol-Urganci I, van der Meulen JH, Mahmood TA, Richmond DH, Dougall A, et al. Vaginal birth after caesarean section: A cohort study investigating factors associated with its uptake and success. BJOG. 2014; 121:183-92.

11. Raja JF, Bangash KT, Mahmud G. VBAC Scoring: Successful vaginal delivery in previous one 
caesarean section in induced labor. J Pak Med Assoc. 2013;63(9):1147-51.

12. Doshi HU, Jain RK, Vazirani AA. Prognostic factors for successful vaginal birth after caesarean section Analysis of 162 cases. J Obstet Gynecol India. 2010; 60(6):498-502.

13. Goyal SS, Tiwari M, Hariharan C, Shrivastava DS. Outcome of post caesarean pregnancy and comparison of maternal and fetal outcome following vaginal birth versus repeat caesarean section in a rural hospital. Int $\mathbf{J}$ Reprod Contracept Obstet Gynecol. 2013;2(1):16-22.

14. Bujold E, Gauthier RJ. Risk of uterine rupture associated with an interdelivery interval between 18 and 24 months. Obstet Gynecol. 2010;115:1003-6.

15. Kessous R, Sheiner E. Is there an association between short interval from previous cesarean section and adverse obstetric and perinatal outcome? J Matern Fetal Neonatal Med. 2013;26:1003-6.

16. Birara M and Gebrehiwot Y. Factors associated with success of vaginal birth after one caesarean section (VBAC) at three teaching hospitals in Addis Ababa, Ethopia: a case control study. BMC Pregnancy Childbirth. 2013;13:31.

17. Latika, Kaur G, Singh S. To study the maternal and perinatal outcome following vaginal birth after caesarean section after one previous lower segment caesarean section. Int $\mathbf{J}$ Reprod Contracep Obstet Gynaecol. 2015;4(3):658-63.

18. Mishra N, Taori N, Misri A. Fetomaternal outcome of pregnancy with previous cesarean section. J Evolution Med and Dent Sci. 2014;3(47):11369-78.

19. Pembe AB, Othman MK. Pregnancy outcome after one previous caesarean section at a tertiary university teaching hospital in Tanzania. Tanzania J Health Res. 2010;12(3):188-94.

20. Guiliano M, Closset E, Therby D, LeGoueff F, Deruelle P, Subtil D. Signs, symptoms and complications of complete and partial uterine ruptures during pregnancy and delivery. Eur J Obstet Gynecol Reprod Biol. 2014;179:130-4.

21. Eskandar M, Aboud J, Alshahrani M, Hassanein M, Alyamani A. Optimization of clinical outcome of women with previous one lower segment caesarean section. Open Jpresentnal of Obstetrics and Gynaecology.2012;2(3): 265-269.

22. Eskandar M, Aboud J, Alshahrani M, Hassanein M, Alyamani A. Optimization of clinical outcome of women with previous one lower segment cesarean section. Open J Obstet Gynecol. 2012;2(03):265.

Cite this article as: Jain R. Safety of vaginal birth after single previous lower segment. Int J Reprod Contracept Obstet Gynecol 2018;7:2596-602. 